\title{
R6 - DESENVOLVIMENTO DE TESTE RÁPIDO PARA TITULAÇÃO DE ANTICORPOS CONTRA ANTÍGENO NÃO TREPONÊMICO DA SÍFILIS
} \author{
Domingos da Silva ${ }^{1}$. \\ ${ }^{1}$ Laboratório de Tecnologia Diagnóstica, Bio-Manguinhos, Fiocruz. \\ ${ }^{2}$ Programa de Reativos para Diagnósticos, Bio-Manguinhos, Fiocruz.
}

Nara Mazarakis Rubim ${ }^{1}$, Michel Vergne Sucupira ${ }^{1}$, Antonio G. P. Ferreira ${ }^{2}$, Edimilson

\section{OBJETIVO}

Obter teste rápido do tipo fluxo lateral de baixo custo e alta sensibilidade capaz de detectar e semi-quantificar anticorpos contra o antígeno não treponêmico da sífilis.

\section{MÉTODOS}

O antígeno Não Treponêmico é constituído por micelas formadas por cardiolipina, colesterol e lecitina, que constituem o VDRL (Venereal Diagnostics Research Laboratories). Anticorpos Não Treponêmicos são indicadores de infecção ativa, pois a redução do seu título pode indicar sucesso da terapia enquanto o aumento pode representar um possível relapso ou reinfecção. O antígeno Não Treponêmico foi impregnado em membrana de nitrocelulose utilizando diferentes abordagens: aplicado em concentrações crescentes, decrescentes e na mesma concentração produzindo um formato de teste com inúmeras bandas e acrescido do controle com proteína $\mathrm{A}$. Os testes foram montados e avaliados frente a inúmeras amostras de soros, além de painéis internacionais para sífilis, visando a obtenção de provas de conceito.

\section{RESULTADOS}

Os resultados preliminares indicam que a melhor conformação para o teste foi a obtida com a mesma concentração do antígeno Não Treponêmico impregnado nas bandas testes. As amostras com títulos mais altos correlacionaram bem com a quantidade de bandas e foram marcando por esgotamento do anticorpo na medida em que o fluxo da amostra percorria a área teste evidenciando uma maior intensidade de marcação na primeira banda. Estes resultados preliminares sugerem uma possibilidade de utilizar o antígeno 
Não Treponêmico em teste rápido de fluxo lateral para uma quantificação de anticorpos contra a sífilis.

\section{CONCLUSÃO}

O teste do VDRL é o mais utilizado para a confirmação do diagnóstico da sífilis, porém, depende da utilização de equipamentos disponíveis apenas em laboratórios e especialmente da experiência do usuário. A proposta deste teste é possibilitar o uso deste antígeno em uma semi-quantificação do anticorpo na detecção da sífilis e para o acompanhamento da queda do título durante o tratamento. A forma de fluxo lateral possibilita a utilização deste teste em "beira de leito" e em locais e populações de difícil acesso. O resultado preliminar é promissor e nos inspira a continuar o desenvolvimento. 